\title{
The Impact of Structural Adjustment Policies on Fertilizers Market in Bangladesh
}

\author{
Islam Mohd. Nazrul (United Graduate School of Agricultural Science, Tottori University • \\ Bangladesh Agricultural Research Institute) \\ Akira Ishida (Faculty of Life and Environmental Science, Shimane University) \\ Kenji Taniguchi (Faculty of Life and Environmental Science, Shimane University)
}

\section{Introduction}

Different types of fertilizers are used in Bangladesh, among them Urea is the first, Triple Super Phosphate (TSP) is the second and Mureate of Potash (MP) is the third in position. These three types of fertilizers consist on an average more than $90 \%$ of total fertilizer yearly consumed in the country [13] and policy focus on fertilizer largely dealt with these fertilizers. Urea is solely produced domestically, TSP is produced domestically (more or less $15 \%$ ) and also imported, and MP is imported to meet the demand. Initially, these fertilizers were highly subsidized. With the widespread of seedfertilizer-water technology, the consumption of chemical fertilizers has increased in Bangladesh. Since fertilizer subsidy was reduced after the emergence of Bangladesh (in 1971), the overall rate of subsidy on these three kinds of fertilizers has dropped from $57 \%$ in $1975-76$ to $25 \%$ in $1983-84$. However, the government expenditure on the fertilizer subsidy was increased due to rapid increase in fertilizer use, Taka 854 million to Taka 1426 million within this period [15]. The government faced budgetary constraints for subsidizing the input at a high amount. The donor agencies advised to gradually reduce subsidy on inputs and to encourage privatization of the input markets in order to reduce development expenditures as well as to improve the availability of fertilizer in the right time in the right quantity and also to improve the market efficiency. As a result, a series of privatization and deregulation policies were implemented in the agricultural input market since 1978 known as structural adjustment policies and ended in the year 1992. However, several studies dealt with the total fertilizer consumption, which might be illusive in the contest of major three fertilizers consumed in the country and the debate, on the break date for series of structural adjustment policies is far from settled. Hence, it is inevitable to find out the effective break date occurred in fertilizer consumption for analyzing the impact of structural adjustment policies on fertilizer market. Therefore, the present study is designed to i) determine probable break date in fertilizer consumption occurred due to structural adjustment policies; ii) compare the instabilities of retail price and consumption iii) compare and analyze the fertilizers prices; and iv) suggest some policy guidelines for the fertilizers consumed in the country.

\section{Brief History of Fertilizer Distribution System}

Since the emergence of Bangladesh in the year 1971, the Bangladesh Agricultural Development Corporation (BADC) was the sole agent for procuring fertilizers from local plants and from abroad and for distributing these fertilizers to the farmers through appointed dealers. At that time, the distribution network of BADC included 423 Thana Sales Centres (TSC); a thana is an administrative unit consists of 80-90 villages that sold fertilizers to the dealers and agricultural cooperatives at the village level for retailing to the farmers. There was one flat price for retailing all over the country and in spite of retail sale, the dealers received commission.

Under the USAID project grant, reform policy was introduced with a government order in the year 1978 for fertilizers and then, BADC withdrew TSCs and concentrated wholesale distribution at 97 primary distribution points (PDP) within the year 1978-1983. First step in fertilizer price deregulation 
occurred on $1^{\text {st }}$ April 1984 and the free trading was allowed bellow PDP and dealers could charge at their own at retail level. In the year 1987, the private distributors were permitted to lift larger lot of fertilizer at discount prices from the few BADC centers. Later, from the year 1989, the national level distributors were allowed to lift directly from the domestic factories and BADC port location. BADC was the sole agent for local production, import and for fixing the issue or wholesale price up to 1991 for these three types of fertilizers. Finally, private sector was also allowed to import different type of fertilizer from December 1992 [5]. Thereafter, in the year 1995, urea crisis pointed out that the defective distribution system (oligopolistic structure) at the factory gate created the artificial crisis allover the country and the needs for government role [9]. After the crisis, the government took some policy measures only for domestically produced urea, importing by private sector was stopped and if import is needed, urea will be imported by government agency, i.e. Bangladesh Chemical Industries Corporation (BCIC).

\section{Materials and Methods}

The data used for this study were collected from the Handbook of Agricultural Statistics; Ministry of Agriculture (MOA) of Bangladesh published in 2004 [13], the Statistical Yearbook of Bangladesh; Bangladesh Bureau of Statistics (BBS) [6], Jaim [9] and International Fertilizer Development Centre (IFDC) Office in Bangladesh and State Bank of Bangladesh. For reliability, the data were cross-examined and compared with the data of different sources for more accuracy. On the basis of availability of all required data, finally the study period was selected from 1971 to 2002 .

\subsection{Analytical Technique}

\subsubsection{Analysis for probable break date}

To find out probable break date for fertilizer consumption Chow test was used for time series model with a deterministic trend.

$$
L n Y=\alpha_{0}+\alpha_{1} D+\beta_{0} T+\beta_{1} D T+u_{i}
$$

In the above function where, $\ln Y$ is the logarithm of the variable (s) for per hectare fertilizer (s) consumption; $\mathrm{D}$ is dummy variable, taken value 1 for the period of structural change occurred and 0 otherwise; $\mathrm{T}$ is Time variable; $\alpha_{1}$ is Coefficient of dummy variable, $\beta_{0}$ is growth rate for the period before break date and $\left(\beta_{0}+\beta_{1}\right)$ is growth rate for the period after break date. Thus, for the probable break date, Chow statistics for the $\mathrm{H}_{0}: \alpha_{1}=\beta_{1}=0$ are estimated and their estimated sequences are plotted in graph against the study period and probable break date in fertilizer consumption will be worked out on the basis of highest Chow test result [12]. After that whole study period will be divided into two sub periods; Sub period-I (before the effect of structural adjustment policies) and Sub period-II (after the effect of structural adjustment policies).

\subsubsection{Instability analysis}

Instability in fertilizer price or consumption could be defined as the state in which quantity continue to change with the passage of time in a country. The extent of instability has to be examined in relation to time. Alam [3], Alam and Lingard [4], Kaushik [11], Mitra [14], and Sabur et al. [16] used instability index in time series data for different crops. For a general index of instability in a time series, one may also consider an index as follows: $I=(C V)^{2} \times\left(1-R^{2}\right)$

Where,

$I=$ Instability Index;

$C V=$ Coefficient of variation in fertilizer consumption and $1 \leq C V$; and

$R^{2}=$ Coefficient of determination obtained from linear or non-linear function.

The coefficient of Variation $(C V)$ in fertilizer consumption indicates the extent of variation in a static sense. Usually $C V$ measures the variation in the data not showing any trend. But the time series data always shows some kind of trend, might be linear or non linear. Thus, inclusion of information about trend in the equation of instability might have greater applicability. Hence, a comparison will be made between Sub period-I (before the effect of structural adjustment policies) and Sub period-II (after the effect of structural adjustment policies). 


\section{Results and Discussion}

\subsection{Probable break date in fertilizer consumption}

The chow test results for probable break date in consumption for TSP and MP showed no significant break or changed occurred and so, we considered the total amount of fertilizer consumed in the country for this analysis. For all probable break dates in fertilizer consumption Chow statistics for the null hypothesis of no change occurred $\left(\mathrm{H}_{0}: \alpha_{1}=\beta_{1}=0\right)$ were worked out and plotted in the Figure 3 as a function of probable break dates. Under the assumption that the break date of fertilizer consumption is unknown and took place around these times, the Chow test was done. The Figure 1 shows that chow test was found to be the highest in the year 1986-87 and it was 40.09 since it is greater than Bai and Perron provide the critical value, which is 16.6 at one percent significance level [12]. Although, fertilizer market liberalization had proceed in gradual fashion since 1978, the most effective measure (deregulation of price) was taken in the early 1984 and the traders had the freedom for charging retail prices. The licensing process for wholesalers was effectively abolished; and restriction on fertilizers movement and trading from one area to another were removed around this time. So, it is very much rational that the take-off time of SAP is occurred in the year 1986-87. Hence, the total time period was splitted into two sub periods; one is sub-period-1 (1971-72 to 1986-87), before the effect of structural adjustment policies and another is sub-period-2 (1987-88 to 2001-02), after the effect of structural adjustment policies.

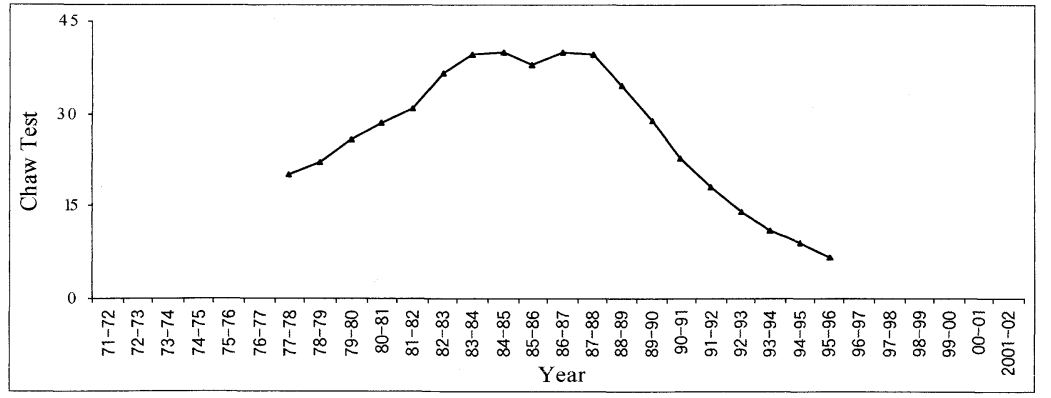

Figure 1 Testing for probable break date on per hectare fertilizer consumption in Bangladesh.

\subsection{Instability index for fertilizer consumption and retail price}

The estimated instability indexes presented in Table 1 is an attempt to examine the nature and degree of instability in the amount of different types of fertilizer consumed and its retail prices in Bangladesh for the two periods. The instability is one of the important decision parameter for agricultural production. According to Gangwar and George [7] and Mitra [14], knowledge of instability might be helpful to the farmers for making suitable production and investment decision. The instability analysis showed that the instability was the highest during the year 1971-72 to 1986-87 for consumption of MP and it was the highest in the case of retail price of urea. On the other hand, during the sub-period 2 i.e., 1987-88 to 2001-02 instabilities were the highest for the TSP both for quantity consumed and real price, and increased approximately by 2411 percent and 185 percent, respectively. The instabilities in consumption and retail price of MP and TSP were found to be increase in sub-period 2 (1987-88 to 2001-02) by 88 percent, 67 percent and 1161 percent, 91 percent, respectively. But both the consumption and retail price instabilities have reduced during the sub-period 2 (198788 to 2001-02) in the cases of urea by 11percent, 90 percent and the retail price instability reduced more than consumption instability. In spite of these, instabilities in the consumption have increased much more than retail price instabilities for MP and TSP in the sub-period 2. Hence it might be concluded, except the case of urea, these findings partially belie the arguments by vested-interest groups that impact of SAP on fertilizer market has been counterproductive in Bangladesh.

\subsection{Prices of different fer- tilizers}

Private sector participation in procurement and distribution of fertilizer has given rise to fertilizers prices 
Table 1 Estimated instability indexes of different types of fertilizer for two sub periods.

\begin{tabular}{l|l|r|r|r}
\hline \multirow{2}{*}{\multicolumn{2}{c|}{ Description }} & \multicolumn{2}{|c|}{ Instability Index } & \multirow{2}{*}{$\begin{array}{c}\text { Change over } \\
\text { sub-period 1 }\end{array}$} \\
\cline { 3 - 5 } \multirow{2}{*}{ MP } & Quantity consumed & Sub-period 1 & Sub-period 2 & 87.58 \\
\cline { 2 - 5 } & Retail Price & 76.37 & 420.88 & 66.68 \\
\hline \multirow{2}{*}{ TSP } & Quantity consumed & 136.89 & 127.77 & 1661.22 \\
\cline { 2 - 5 } & Retail Price & 96.54 & 2410.93 & 91.45 \\
\hline \multirow{2}{*}{ Urea } & Quantity consumed & 63.24 & 56.83 & -10.75 \\
\cline { 2 - 5 } & Retail Price & 177.17 & 18.05 & -89.81 \\
\hline \multirow{2}{*}{ Total Fertilizer } & Quantity consumed & 72.17 & 62.39 & -13.55 \\
\cline { 2 - 5 } & Retail Price & 131.14 & 26.26 & -79.87 \\
\hline
\end{tabular}

Exponential growth function was used for deriving $\mathrm{R}^{2}$

specially for TSP and MP over urea. Even though, Ahmed [1], Infanger, Samad and Hooker [8], and Zohir [17] found that fertilizers prices in the retail level appeared to be highly competitive. Even though, the private sector participation in procurement and distribution of fertilizer (specially for TSP and MP) has has given rise several vice: i) some doubts still persist that the trader at the import level or apex level might turn to oligopolistic or cartel structure; ii) it has been easy for the traders to fool the farmers and sale poor quality fertilizer at a price normally associated with higher quality fertilizer. As the (ii) is beyond our study, we will try to examine the possibilities of existing oligopolistic/ cartel structure at import or apex level other than retail level.

The Figure 2 shows that upto $1986-87$ the retail price of urea is higher than the retail prices of TSP \& MP. Since the year 1986-87, the retail price of TSP has started to rise and fluctuate, and for MP it was since 1990-91. The Figure 3 showed the differences between import/ issue prices and retail prices of different fertilizers in different years. The figure clearly shows that the margins are more for TSP and MP rather than urea, though the marketing channel is same for all types of fertilizers. Except the case of 1995 and 1996, there was a urea crisis all over the country in the year 1995. It implies that that the traders are earning much profit compared to urea.

Moreover, issue price of urea is lower than international prices, but import prices for TSP and MP in the country are much higher compared to international prices (Table 2). It also clearly suggests the existence of price oligopolistic/cartel structure in the TSP and MP fertilizer distribution system at import or apex level other than retail level. As a result retail prices of TSP and MP are also higher compared to some Asian countries (Table 3).

\subsection{Policy remarks}

As most of the urea consumed in the country is produced domestically and in a sense pricing of urea is controlled by public sector. So, the price of urea is comparatively less than other fertilizers. In contrast, the MP and TSP fertilizers are mostly imported and might ultimately turn to oligopolistic/cartel structure at import or apex level. But several studies stated that the competitive market had been working at the retail level for

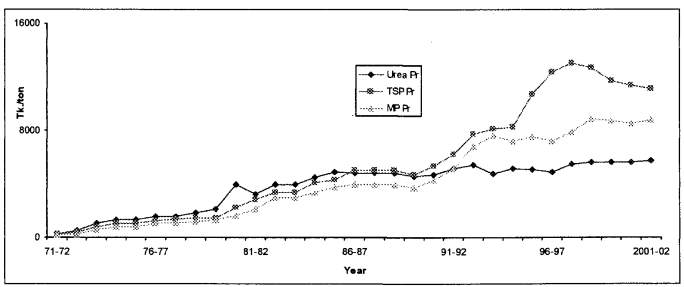

Figure 2 Retail price of different fertilizers during the year 1971-72 to 2001-02

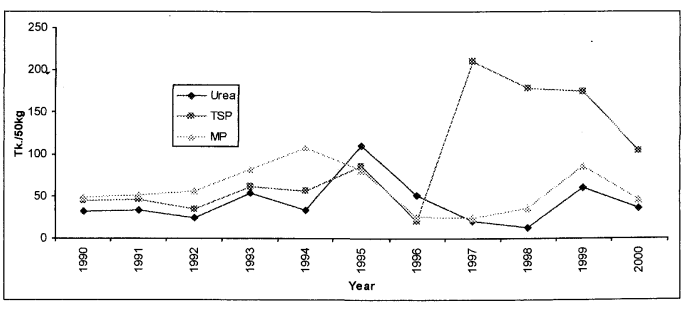

Figure 3 Differences of reatil price and issue/import prices of chemical fertilizers

Source: [6] \& [13] 
all types of fertilizers. The MP and TSP fertilizers uses have drastically decreased relative to urea since the process of reform began to take root [1] and retail price increased sharply than urea and instability increased for the both the cases. It is very alarming situation for crop production and as well as soil health in the long run. Since the TSP and MP are crucial to long-run conservation of soil quality, should be prices relatively cheaply compared to urea. Even if possible import subsidy to some extent should be given or could be imported all major fertilizers by BCIC (as urea) than sold to the traders and or carefully designed the mechanism for ensuring competition at the import or apex level for MP and TSP.

\section{Conclusion}

The fertilizer market in Bangladesh had been privatized and deregulated in gradual fashion since 1978 and ended in 1992. The analysis for probable break date shows that the break date in fertilizer consumption has occurred in the year 1986-87. Hence, for inabilities and as well as prices, com- parison were made for before and after the impact of structural adjustment policies on fertilizers consumption. After the impact of structural adjustment policies on fertilizer consumption, the instabilities in consumption and retail price for MP and TSP were found to be increased. The instabilities in the consumption have increased much more than the instabilities of retail price for MP and TSP after the impact of the structural adjustment policies. But in the case of urea, the consumption and retail price instabilities have reduced during this period. Moreover, the MP and TSP uses have drastically decreased retail price and marketing margins increased sharply relative to urea since the process of reform began to take root. Since the TSP and MP are crucial to long-run conservation of soil quality, should be prices relatively cheaply compared to urea. Even if possible import subsidy to some extent should be given or could be imported all major fertilizers by BCIC (as urea) than be sold to the traders and or carefully designed the mechanism for ensuring competition at the import or apex level for MP and TSP.

Table 2 Issue/import prices in Bangladesh and international prices of different types of chemical fertilizers (US\$/ton).

\begin{tabular}{l|r|r|r|r|r|r}
\hline \multirow{2}{*}{ Year } & \multicolumn{2}{|c|}{ Issue/import prices in Bangaldesh } & \multicolumn{3}{c}{ International prices } \\
\cline { 2 - 7 } & Urea & \multicolumn{1}{c|}{ TSP } & \multicolumn{1}{c|}{ MP } & $\begin{array}{c}\text { Urea } \\
\text { (E.Europe) }\end{array}$ & $\begin{array}{c}\text { TSP } \\
\text { (US Gulf) }\end{array}$ & \multicolumn{1}{c}{$\begin{array}{c}\text { MP } \\
\text { (CIS) }\end{array}$} \\
\hline 1993 & 108.00 & 169.00 & 138.00 & 82.00 & 114.71 & 70.94 \\
\hline 1994 & 101.00 & 183.00 & 139.00 & 123.00 & 136.00 & 72.00 \\
\hline 1995 & 92.00 & 182.00 & 140.00 & 186.00 & 162.00 & 80.00 \\
\hline 1996 & 91.00 & 207.00 & 155.00 & 180.00 & 177.00 & 84.00 \\
\hline 1997 & 105.00 & 190.00 & 156.00 & 117.00 & 167.00 & 88.00 \\
\hline 1998 & 112.00 & 202.00 & 152.00 & 84.00 & 159.00 & 94.00 \\
\hline 1999 & 92.00 & 182.00 & 152.00 & 67.00 & 146.00 & 103.00 \\
\hline 2000 & 94.00 & 178.00 & 147.00 & 103.00 & 129.00 & 101.00 \\
\hline 2001 & 88.00 & 176.00 & 145.00 & 96.00 & 124.00 & 98.00 \\
\hline
\end{tabular}

Source: Estimated from MOA, 2004 and www.fadinap.org (02-08-2005)

Table 3 Retail prices of chemical fertilizers in some Asian countries (US\$/ton).

\begin{tabular}{l|r|r|r|r|r|r}
\hline \multirow{2}{*}{ Country } & \multicolumn{3}{|c|}{1993} & \multicolumn{1}{c}{2000} & \multicolumn{1}{c}{ MP } \\
\cline { 2 - 7 } & Urea & TSP & MP & Urea & TSP & 164.00 \\
\hline Bangladesh & 118.00 & 202.00 & 206.00 & 108.00 & 219.00 & 94.00 \\
\hline India & $87.32^{*}$ & - & 117.00 & $101.00^{*}$ & - & - \\
\hline Nepal & 140.00 & 162.00 & 122.00 & 132.00 & - & - \\
\hline Pakistan & 146.00 & 129.00 & - & 121.00 & 211.00 & 193.00 \\
\hline Sri Lanka & 209.00 & 208.00 & 192.00 & $84.00^{*}$ & 251.00 & 157.00 \\
\hline China & 172.00 & 164.00 & - & 146.00 & - & - \\
\hline
\end{tabular}

Source: Calculated from the websites of www. Sdnbd.org and www.fdinap.org (02-08-2005)

* Subsidy provided by government 


\section{References}

[1] Ahmed, R "Assessment of Past Agricultural Polices" Chapter-3; Bangladesh Agriculture in The $21^{\text {st }}$ Century. The Wprld Bank Bangladesh. http//: wbln0018.worldbank.org/ lo web sites/bangladesh Web.nsf/...June 28, 2005.

[2] Akteruzzaman, M. and W. M. H. Jaim "The Impact of Privatization and Deregulation on New Technology Diffusion and Agricultural Growth Performance in Bangladesh: A Macro View," Bangladesh Journal of Agricultural Economics, XXII (1), 1999. pp.51-62.

[3] Alam, S. "Yield Growth Senario and the Factors Contributing to Output Changes of Different Rice Varieties and Types in Bangladesh," Bangladesh Journal of Agricultural Economics, Vol. XV. No. 2, 1992; pp.6-19.

[4] Alam, S and J. Lingard. "Factors Influencing Yield Growth and Production Instability of Jute in Bangladesh," Bangladesh Journal of Agricultural Economics, Vol. XIV. No. 1. 1991; pp.19-35.

[5] Baananate, C. A., J. Henao and X. Wan. "Fertilizer Subsidy Removals in Bangladesh: An Assessment of the Impact of Fertilizer Use, Crop Yelds and Profits of Farmers," A report submitted to the International Fertilizer Development Centre, Albama, USA. 1993.

[6] Bangladesh Bureau of Statistics (BBS). Statistical Yearbook of Bangladesh, Statistical Division, Ministry of Planning, Government of the People Republic's of Bangladesh. Dhaka., various issues (1974-2001).

[ 7 ] Gangwar, A. C. and M. V. George. "Income, Price and Yield Variability for Principal Crops and Cropping Pattern in Haryana State," Agricultural Situation in India, No. 24, 2, 1971; pp.70-80.

[8] Infanger, C. L., A. Samad and R. W. Hooker. Final Evalution: Bangladesh Fertilizer Distribution Project. Dhaka; Report, IFDC, 1988.
[9] Jaim, W. M. H. Agricultural Development in Bangladesh. Views and Reviews, Research Monograph Series No. 1. Joint Study on Rural Development Experiment. Japan International Co-operation Agency (JICA), Bangladesh Office. Gulshan, Dhaka, 1995; pp.61-63.

[10] Jaim, W. M. H. and M. Nazrul Islam. "Was Fertilizer Distribution System Alone Responsible for Shortfall of Boro Rice Production in Bangladesh in 1995?" Bangladesh Journal of Agricultural Economics, XX (2), 1997; pp.67-80.

[11] Kawshik, K. K. "Growth and Instability of Oilseeds Production," Indian Journal of Agricultural Economics, Vol. 48. No. 3, 1993.

[12] Kurosaki, T. "Specialization and diversification in Agricultural Transformation: The Case of West Punjab, 1903-92," American Journal of Agricultural Economics, Vol. 85, No. 2, 2003; pp.372-386.

[13] Ministry of Agriculture (MOA). "Handbook of Agricultural Statistics," Sector Monitoring Unit, Ministry of Agriculture, Government of the People's Republic of Bangladesh, Dhaka, 2004. pp.40-60.

[14] Mitra, T. K. "Growth and Instability of Agriculture Prices in West Bengal, A Note," Indian Journal of Agricultural Economics, XLIV (1), 1989; pp.67-71.

[15] Osmani, S. R. and M. A. Quasem. Pricing and Subsidy Policy for Bangladesh Agriculture. Bangladesh, Research Monograph No. 11, Institute of Development Studies, E-17 Agargaon, Dhaka 1990; pp.27-40 \& 215-223.

[16] Sabur, S. A. and M. A. M. Miah. "The Performance of CDP Crops Under Free Market System in Bangladesh," Farm Economy, Vol. 10, 1995; pp.33-48.

[17] Zohir S., "Impact of Reforms in Agricultural Input Markets on Crop Sector Profitability in Bangladesh," A Research Report (Final Draft), Bangladesh Institute of Development Studies; Shere Banglanaga, Dhaka; 2000 . 